\title{
APPLYING AHP AND RATING MODEL FOR PRIORITIZING IRAN PROVINCES AND ESTABLISHMENT OF SOLAR WOOD DRYING
}

\author{
Majid Azizi \\ Wood and paper sciences and technology Department \\ Faculty of Natural Resources \\ University of Tehran \\ Email: mazizi@ut.ac.ir \\ Nemat Mohebbi \\ Wood and paper sciences and technology Department \\ Faculty of Natural Resources \\ University of Tehran \\ Email: mohebbi.nemat@yahoo.com
}

\begin{abstract}
ABSTARCT
Solar energy is one of the free and clean sources of energy supply without any destructive influence on the environment. Solar energy has been used in different forms for a long time. Concentrators of solar radiation can be used to produce unlimited, clean and free energy and save fossil fuels considerably. One of important applications of solar energy is to manufacture solar wood drying units. Iran has been located in an appropriate situation in the world with respect to receiving solar energy. For identifying and determining the best location for establishing solar wood drying; first experts of kiln wood drying were interviewed for preliminary investigation. As the second step, hierarchy of criteria was designed and weighing values of them were calculated by AHP. In the third step, model was used rating for prioritizing capable provinces. Results showed that Qom province, with average temperature, has the highest priority as a criterion and alternative.
\end{abstract}

Keywords: Solar energy, wood drying, AHP, criteria, province, location 


\section{Introduction}

Solar energy is one of the freest and cleanest sources of energy in the world which has no destructive effect on the environment. It has been used in various ways by the people for a long time. In the case of solar radiation for 40 days required energy for one century can be reserved. Thus by applying solar radiation concentrators along with the use of this free and clean and endless energy, the saving of fossil fuel consumption will also be possible.

Iran has been located between 25-40 degrees of northern latitude and regarding solar energy receiving has highest level in the world. The amount of sun radiation is between 1800-2200 $(\mathrm{kWh}) / \mathrm{m}^{3}$ in a year which is higher than world average. In Iran more than 280 days are sunny which is very notable [1]. One of the possible and valuable applications of solar energy is in wood industry and manufacturing solar wood dryer. In solar dryers, solar energy is used for drying material indirectly or directly and air flow helps to moisture displacement naturally or in an under controlled way which accelerate wood drying process.

\section{Literature review}

The solar drying kiln is the most cost effective way for the craftsman to get quality boards for wood working from green lumber. Today there are many band saw operators cutting boards from trees that grow in abundance in much of America. The solar kiln is the link between this resource and the shop. A wood kiln is any space used for controlling heat and humidity where lumber is dried. The solar drying kiln harnesses the free energy of the sun. It operates on the regular cycle of day and night to prevent wood stress that can ruin lumber in other systems [2]. Solar drying is one of the important thermal applications, where solar energy can be utilized efficiently. Drying depends on the air ability to evaporate water (drying potential); hence its relative humidity is a key factor. The lower the relative humidity of the drying air, the more water of air evaporates from the product, resulting in lower final product moisture content. Drying potential is influenced by air temperature as well as relative humidity. Much work on solar energy has been concerned with the use of solar heated air (naturally or mechanically circulated) to remove the moisture from materials placed inside an enclosure where the heated air is blown past the material. Solar drying provides up to 50\% reduction of final moisture content and drying time compared with air-drying [3]. Over the last few decades, much research and development has been conducted into the use of solar kilns for timber drying. This has led to the commercial use and availability of solar kilns in the timber industry over recent years [4]. 


\section{Hypothesis/Objectives}

The present study aims to identify the effective criteria on best site selection to establish solar wood drying units in Iran via AHP and rating model.

\section{Research Design/ Methodology}

First step for finding capable provinces of Iran to establish solar wood drying units 30 questionnaires were distributed among qualified people who were academic members (10\%), Industries and mines organization; planning and budget organization (14\%), members of furniture union (30\%) and owners of industries (46\%) and provinces which had no capability for establishing solar wood drying units were deleted. Capable Provinces which had appropriate site to establish solar wood drying units are as follow: Tehran, Qom, Khorasan Razavi, Markazi, Fars, Mazandaran, Isfahan, Ghazvin, Alborz. Second step for identifying effective criteria in site selection of solar wood drying units establishment, a hierarchy (fig.1) with five major criteria was planned then 20 questionnaires were distributed among experts of wood drying units. Collected data processed in expert choice software and weighing values of criteria and sub criteria were determined. 


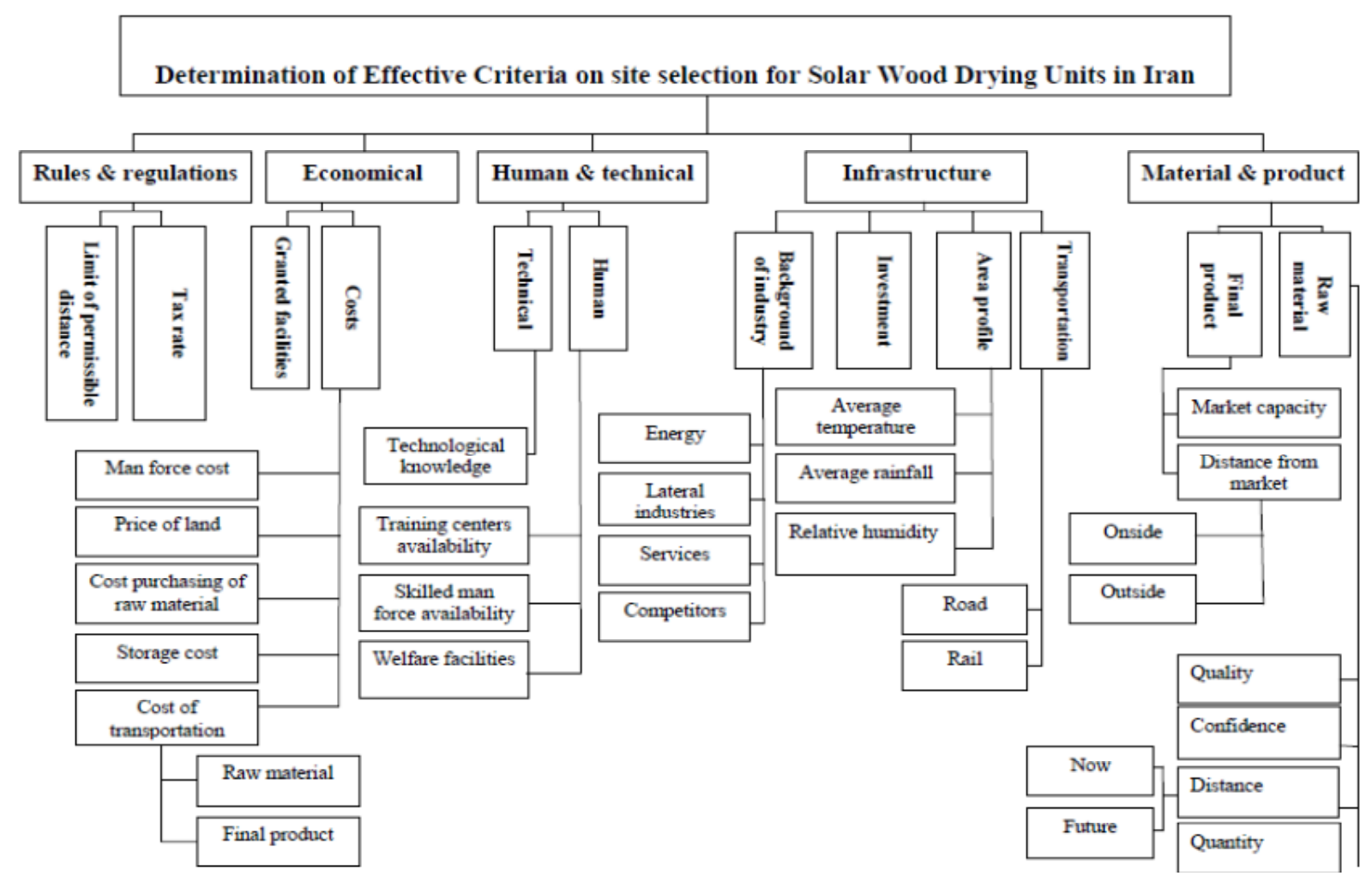

Figure 1: Hierarchy of effective criteria in site selection of solar wood drying units

\section{Data/ Model Analysis}

With using rating model of expert choice software each recognized criterion of second step was divided in different intensities and amounts of intensities were calculated regarding comparisons. Then the relations between quality and quantity amounts of these criteria with intensities were determined. The intensity importance rate of these criteria which has been obtained in first step was studied for each capable province.

\section{Limitations}

Climate changes is a limitation in this study. We studied above mentioned provinces in a stable situation regarding climate. The changes can be considered for future researches.

\section{Conclusions}

\subsection{Average of air temperature or incoming energy from the sun}


The result shows that below average temperature criteria, granted facilities, market capacity, labor force availability and price of raw material, have highest priority for site selection of solar wood drying units respectively.

Radiation is amount of energy of electromagnetic on area unit per unit of time which has been named as flux. Solar energy is an opportunity which there is extended programs for developing its application in the world. Programming for solar energy application is a capacity building for using a very large resource which is not comparable with other current energy resources because amount of solar energy is more than several times of energy consumption which man uses energy throughout the year, that is accessible (solar energy) on the earth per hour.

The application of enormous solar energy resources for electricity energy production, dynamic usage, heating generation for areas and buildings, drying agricultural products, chemical changes and so on, are the strategies which have been started in former years. The amount of solar energy obtained from sun radiation in one point of earth area throughout the year, depends on the intensity and duration of sun radiation in that region.

Results of the interview with the experts indicated that maximum radiation of sun throughout the year in the region is the most important criteria for site selection of solar wood drying units. Iran has various climates. Air temperatures, humidity, radiation of sun, rate of rain are different in the regions. Hence it will be logical that the average of air temperature or incoming energy from the sun in each region has the highest priority for site selection of solar wood drying units.

\subsection{Result of prioritizing items using rating model}

Qom province (see figure 2) is not only the closest province to the largest furniture consumption market of Iran but also has appropriate infrastructure similar ideal transportation network between Qom and Tehran, many equipped industrial towns with low distance to Tehran, extended facilities and preferences for investment attractions. For these reasons Qom province actually has changed the largest regional industrial town near to Tehran. Permitted distance for establishing industrial units from Tehran as center of Iran is more than $120 \mathrm{~km}$; in this regard Qom province obtains higher priority to establish industrial units. According to the existence of 
skillful man force criteria, Qom province has good background in wood industry and in this province access to skillful and knowledgeable man force has proper situation.

In this province man force cost and price of land for establishing a factory is lower than Tehran. Average of air temperature or incoming energy from the sun in Qom province with weighing value 0.308 has favorite situation so that division of different regions of Iran regarding average of air temperature shows this province is located in the region with high radiation of sun. Accordingly the selection of Qom province as an appropriate alternative for establishing solar wood drying units is logical and justified.

\begin{tabular}{|c|c|}
\hline Ideal mode & \\
\hline Alternative & Total \\
\hline$\checkmark$ TEHRAN & .326 \\
\hline$\checkmark \mathrm{QOM}$ & .331 \\
\hline$\checkmark$ ALBORZ & .271 \\
\hline$\checkmark Q A Z V I N$ & .145 \\
\hline$\checkmark$ MARKAZI & .239 \\
\hline$\checkmark M A Z A N D A R A N$ & .262 \\
\hline$\checkmark$ FARS & .244 \\
\hline$\checkmark$ ESFAHAN & .260 \\
\hline$\checkmark$ KHORASAN & .209 \\
\hline
\end{tabular}

Figure 2: Outcome of alternatives priority by Rating model

\section{Key References}

[1] Scientific, technical and statistical information provided by SANA (renewable energy organization of Iran), http://www.suna.org.ir/fa/home

[2] John Wilson, 2006. Solar drying kilns: A cost effective and efficient way to take green board to usable lumber, Popular wood working, pp: 74-79

Http://washtenawcd. org/ downloads/solarkiln

[3] Helwa N., Khater H. A., 2004. Enayet M., Hashish M., Experimental Evaluation of Solar Kiln for Drying Wood, DRYING TECHNOLOGY journal: Vol. 22, No. 4, pp. 703-717

[4] Desch, H.E., Dinwoodie, J.M., 1996. Timber: Structure, Properties, Conversion and use. London: Macmillan Press Ltd 